\title{
Theoretical analysis of the ways to enhance the ability of the government's public service
}

\author{
Li Pengfei* \\ Yunnan University of Finance and Economics \\ (13888186161@126.com)
}

\author{
Yin Zhaoyi \\ Yunnan University of Finance and Economics \\ (460745828@qq.com)
}

\begin{abstract}
Enhance the ability of the government's public service, it is necessary to make a theoretical analysis from the human perspective. From the origin, the nature and mission of the government, gradually establish the service concept, exercise public power properly, make a scientific public decision are the three most important ways.
\end{abstract}

Keywords-The public service ability; Power ; Decision making; The government

\section{INTRODUCTION}

Any government has Class Nature and Publicity. The class nature means the government to safeguard the interests of the ruling class, to suppress the resistance of the ruled class, attribute of safeguarding national sovereignty . Publicity means the government management of social public affairs. The class nature determines functions of political domination. The publicity determines functions of public service. The four aspects of humanity contradiction, like relationship between public and private, animal and culture determined the dual attributes of the government . In terms of relationship between the public and the private, reflect the conflict between selfishness in DNA and gregarious in real living conditions. In terms of culture and animal, reflect the conflict between the individual and collective development. The all-round development of people is not only the individual's all-round development, but all-round development of human beings. In the process of human development, the quantity, the quality and range of public services are important parameters. However, in modern society the increased demand of citizens for public service, the importance of government's public service function, make us to think how to efficiently provide public services? There are many people analysis the ways from the aspect of technology and tools, but rare people analysis the ways from the theory and value level. For this reason, this paper will makes a preliminary study on human nature theory. ${ }^{1}$

\section{Gradually Establish the Service ConcePt}

The government improve the public service ability, first must establish the service concept. Establish service concept is the key to change management ideas for the service concept.

\footnotetext{
${ }^{1}$ Li Pengfei,male,1971,Professor,Chairman of Department of Political Science,School of Public Management(SPM), Yunnan University of Finance and Economics Yin Zhaoyi,female,1993,Graduate Student,Major:Administrative Management,Yunnan University of Finance and Economics
}

Back in the history of the world, in the agricultural society, the country emphasis the ruling idea, and established a power governance model, power governance type mode is a kind of govern pattern rely on power. In the power structure of the pyramid, the king in the top of pyramid and the ruling class through from top to bottom, can not overstep the level to control the power relations the domination of society. Rule at the core of the main line has been around power gain, exercise and consolidate. The power of selfishness, imperious, cruel and brutal in national and community level can be found everywhere, the human nature of self-interest, animal reflect incisively and vividly. Legal and moral means of governance in agricultural society, in fact, are under the rule of the ruling means, is not in the modern significance of the rule of law and rule of virtue.

In the industrial society, the country emphasizes the management philosophy, and established a model of rule of law. Finally, as a kind of law in the above the king's public will and appear, although it actually reflect the will of a part is not all, but it is undoubtedly a great progress of human history, because it is human digestion of animal, selfishness, public publicity, culture began. Why do you say? Because in the animal kingdom, generally only one leader group living animals, such as wolves, sheep, elephants and so on. As the same as the social life of human beings, there is a group leader, although only a part but not all people. Therefore, it is slowly human out of self-interest, animal, constantly generate publicity and culture. In the industrial society, the subject of management revolves around three main line of laws, policies and institutions, laws, policies and institutions of the moral thinking has been a perfect system, appropriate policies and reasonable legal important motivation.

In the post industrial society, many countries began to emphasize the concept of service. Therefore, it is necessary to establish a governance model is a type social governance model of rule of virtue. Virtue type social management mode and the agricultural society, industrial society governance model is not the same, mainly reflected in the following aspects: (1) the diversification of the governance main body. Not only a government social governance body, also including non-governmental public organizations, enterprises and citizens. The subject of governance is a relationship between democracy and equality. (2) the diversity of governance mode. Perfect policy, laws and regulations are still an important methods of governance, but improve the basis and prerequisite is a broad consultation between citizens. 
Network and electronic means to make extensive consultation possible. (3) the goal of governance culture. The essence of culture is the relationship between citizens equality and personal happiness. This is significantly eliminate animal and human self-interest, make public the beginning of the culture and the public.

Can be seen from the above analysis, service and management are two fundamentally different concepts: (1) the relationship between the citizens are completely different. The management emphasis is the advantaged position of civil servants, and the service emphasizes the relationship between civil servants and the equality of citizens, that is equal to the relationship between the government and society. (2) different orientations to the problem. Guided by passive solve the problem of what, emphasize the civil servant's administrative behavior of one-way and initiative; Is the service is to satisfy the needs of the public oriented, emphasizing administrative behavior of interaction and harmony, because in order to satisfy the needs of citizens, it is necessary to establish harmonious relationship with the citizens, in order to make a perfect and effective policies and laws. (3) the different ways of solving problems. Administrator advocate to control the way to solve public problems, highlight the control ability of the government, reflects the civil servants and the citizens in the unequal relationship: in fact, civil servants in the active, strong position, the public in a passive, weak position. The service is to discuss ways to meet the needs of citizens, advocated consultation, dialogue and compromise the way to solve the problem, reflect the equality between civil servants and civil. (4) the results of different governance. Management results is to continue to strengthen the unequal relationship between the civil servants and civil, lead to citizen dissatisfaction and resistance, which results in the low efficiency of public service, to reduce the government's legitimacy, and services can stimulate the citizens the enthusiasm and initiative, between the civil servants and public form equal cooperation, mutual support and harmonious coexistence of harmonious administrative relations, to enhance the government's legitimacy.

Therefore, change management concept for the service concept, government is not only to adapt to the objective requirement of human social governance model transformation, the urgent need of self building a serviceoriented government, or the idea of improving the capacity of public services. In the contemporary world, along with the market economy and the further development of global division of labor has become more and more refined, with power to link social relationship are increasingly being to contract to link social relationship replaced, " everyone is a server, and everyone is the service recipient" concept is deep into people's hearts. In view of this, governments after several administrative reform, the public service as an important function of the government and to be strengthened, and this is the way of human society transition response, but also highlights the government's public. These changes with the consistency of the theoretical logic and profound social and historical background. Of course, due to the social form of unbalanced and inconsistent, the final establishment of the service concept is a gradual process.

\section{The Correct EXercise of Public Power}

The first premise of correct exercise of public power is a primary prerequisite for clear the power source, human history of public power sources generally have a several kinds of understanding: (1) think the power comes from god, called the divine right of kings. Such as Chinese's book of songs cloud,Dong said: "the emperor ordered the people", Thomas Aquinas said: "the king is a servant of God." (2) think the power comes from the people, is a reflection of the people's will. As Marx said, the people are the creators of history, the masses is the locomotive of social progress. (3) think the power comes from the social contract ,is the achievement of social contract. Enlightenment scholars Rousseau, Hobbes, Locke, Montesquieu and others have held this view.

In fact, as a kind of reflect human, the power of the relationship between man and material strength, power is a relative concept in nature.From the relationship between people and objects, the early humans in front of the nature is extremely weak, because of human intellectual development is still in its childhood, the human still small in front of the universe, because the universe there are still many unknown to the human things. The nature and the universe formed on human rights. Because of this, religion and philosophy that has been flourishing. From the interpersonal relationship, before the advent of the state in the elders has power objective is because of its generation and life experience than young people more rich and subjective said is because their IQ and EQ is higher than their peers. Therefore, one power initially formed and individual experiences, IQ and EQ. After the appearance of the country, personal power to obtain the various forms, with abdication and hereditary income, democratic election and revolution to seize power income. Since the four forms still exist in the world of government.

For the individual, no matter in what form of power, also has many factors of the individual, whether it's power such as knowledge quality, moral level, IQ and EQ so-called personality charm. Have the public power from first to last. Because: (1) the power comes from others and obedience. If no one else in the world, only one person, this person does not have the power, as social life animal, can not leave others to talk about personal power. (2) power is both for yourself and the purpose of service to others. The essence of human nature in the animal is selfish, this has been confirmed by molecular biology. However, is not for others, it reflects both contradiction and conflict between people's selfish nature, also reflects the essence of human culture in terms of development requirements Therefore, inevitably has the public power. The power is in the contradiction between public and private, and has realized the dialectical unity.

The power of the public how to organize to achieve its function? System created by human beings is representative, that is the majority of people the power entrusted to a few people, by a few people instead of most people to organize the production, to govern the country. Is a representative democracy in the political realm, is the company's corporate governance structure in the field of economy, the society is in the field of civil autonomy organization. As the provider of public service, the government is the representative 
democracy that citizens through the generation of debate democracy to delegate the power to officials at all levels, officials at all levels acting citizens giving power to the client is responsible for, service for the client, trustee to oversee, and realize their own value.

As a result, the basis of the effective supply of public service is simplified to the correct exercise of public power. In the post industrial society, the right to exercise of public power depends not only on the power owner to correctly identify the origin of public power and purpose, and also depends on the political system and the law of public power effective national standards and constraints. In all the legal and institutional arrangements, the effective supply of public services, forever all cannot leave the government administration in the people, to the people, asked should be the people on the overall design.

\section{Scientific Public Policy Decisions}

Which provide public services, provide much public services, to provide some public services? This requires the government makes a scientific decision. The so-called scientific decision-making is based on science and technology, the combination of qualitative and quantitative methods to make decision on public issues. Although the democratic decision is important, but it does not necessarily lead to scientific decision-making. To realize the scientific decision-making, the need for government decision makers in from the way of thinking, consciousness and attitude change efforts in three areas. Mode of thinking is the idea generation and organization form, is the thought of the "engine", consciousness is the actual content of the thought and mental state is individual emotion and volition of individual can make a scientific decision-making on actual effect of "catalyst". The government decision makers, to make public decision-making science, can work from three aspects.

In terms of mentality change, (1)get rid of intolerance, continue to expand the space of thinking. Is the enemy of insularity of mind thinking innovation. "Hobson's effect "advocate to avoid falling into the trap of choice. (2) get rid of fear, civil servants should take the good habit. "To get rid of the gun fight bird effect", this effect is a reflection of human nature is jealous. Jealous of the negative mentality is hurt, a positive attitude is the competition. (3)get rid of psychological, develop a fear of the authority of the spirit of doubt. (4)get rid

\section{REFERENCES}

[1] David Osbome and Ted Gaebler. Reinventing Government:How the Entrepreneurial spirit is Transforming the Public Sector,1992

[2] Karen Miller.Public Sector Reform:Governance in South Africa.Political Science, 2005

[3] Maxwell,JesophAlex.Qualitative Research Design:An Interactive Approach.Sage Publications,Inc,2001

[4] George Haddow,Jane Bullock.An Introduction to Emergency Management Boston:Butterworth Heinemann,2003

[5] William.Waugh,JR.Livingwith Hazards,Dealing with Disasters:An Introduction to Emergency Management.New York:M.E.Sharpe,Inc, 1999

[6] W.Timothy.coombs:Ongoing Crisis Communication Planning,Managing and Responding.London:Sage Publication,Inc, 1993 of the impetuous psychology, develop careful thinking habits. To avoid flighty and impetuous, civil servants should learn to think carefully, reduce entertainment, reduce the toss, strengthen forecast, plan and overall. (5)get rid of the mediocre psychology, the good habit of the pursuit of excellence. To pursue higher competitive, dare and strong, dare to climb high, dare and fast match.

In terms of mode of thinking, (1)pay attention to the application of reverse thinking, combine positive thinking and converse thinking. With the feasibility of policies, measures and feasibility demonstration, truly understand the real meaning of "look before you leap" (2)pay attention to the application of divergent thinking, divergent thinking and convergent thinking together. When the closing of the closing, the right time, do the thinking freely. (3)pay attention to the application of intuitive thinking, intuitive thinking and logical thinking together. (4)pay attention to the application of deductive thinking, the deductive thinking and inductive combination. (5)focus on the application of analytic thinking, civil servants should put together analytic thinking and comprehensive thinking.From the way of thinking of Chinese and Western medicine, combine with the comprehensive thinking and analytic thinking. (6) pay attention to the application of quantitative thinking, the quantitative and qualitative combination of thinking.

From the aspect of ideology, (1) pay attention to the accumulation of knowledge, expand the width of thought. In accordance with the "learn what we need" and "get what we lack" principle, make our knowledge diverse . (2) focus on the theory of learning, and strive to promote thought highly. The height of the theory would have no pertinence and effectiveness of the policy, to understand the relationship between theory, policy and practice. (3)pay attention to practice, efforts to increase the thickness of thought. To know how to practice the purpose of the exercise is to accumulate experience and more job training is an effective way for the accumulation of experience, experience is the valuable fortune of the life. (4)focus on the integration of refining, improve the accuracy of thought. Is to know the screening knowledge and theory, integrated into a block, condensed into a person saying, do a good summary of decision makers. (5) focus on changing ideas, refine ideological purity. Is to know the concept of value is a kind of collective unconscious, to abandon negative values, establish positive advanced values. 